\title{
COVID-19 IMPACT ON SMALL BUSINESSES SURVIVAL
}

Isaura B Flores, University of North Texas at Dallas, Dallas, TX, U.S.A. Elizabeth Muniz, University of North Texas at Dallas, Dallas, TX. U.S.A.

dx.doi.org/10.18374/IJBR-21-1.2

\begin{abstract}
The COVID-19 pandemic had negative effects on all businesses, but the small and medium-sized enterprises (SMEs) were impacted disproportionately. The lockdown and a decline in sales reduced the revenue generating capacity of these businesses, which subjected them to serious financial constraints that threatened their survival. In addition, most of them had to divert their marketing resources to critical functions that could contribute directly to their resilience and survival. Some of the enterprises have been forced to adopt new business models (such as e-commerce, diversification, and automation) to sustain their operations. The labor issues associated with the pandemic contributed directly to the crippling of the SMEs. Farms lost temporary foreign workers, many SMEs reported massive sick leave requests, and a majority of them had to facilitate their workers to perform their duties from home. Financially constrained businesses fired a fraction of their workers or cut their wages. The impacts of this pandemic have been studied extensively, but the benefits related to government loans extended to SMEs have not been explored adequately, which should be considered in the future research.
\end{abstract}

Keywords: Pandemic, SMEs, financial, marketing, models, labor, survival. 